\title{
Reliability differentiation and uniform risk in standards: a critical review and a practical appraisal
}

\author{
Dimitris Diamantidis \\ Miroslav Sykora
}

Dimitris Diamantidis

Ostbayerische Technische Hochschule Regensburg, Germany

Miroslav Sykora

Czech Technical University in Prague, Prague, Czech Republic

Corresponding author: Dimitris Diamantidis, Dimitris.Diamantidisßath-regensburg.de

https://doi.org/10.5592/CO/FTCE.2019.11

Scientific Symposium FUTURE TRENDS IN CIVIL ENGINEERING

Zagreb, Croatia, 17 October 2019 


\section{Reliability differentiation and uniform risk in standards: a critical review and a practical appraisal}

\section{Abstract}

Reliability of structures and infrastructures is a major issue in structural engineering. Structural standards have traditionally been mainly concerned with public safety preventing loss of life or injury; this view has been shifting in recent years towards minimisation of economic loss. This contribution discusses the reliability differentiation principle in modern standards. Its aim is to achieve uniform risk levels for the various classes of structures. Codified criteria for reliability differentiation and risk informed decisions inherent in standards and especially in the Eurocodes are critically reviewed. It is shown that the classification of structures based on consequences of failure is an approach that has not been widely implemented in everyday design. Practical rules for the classification and implementation in design are needed and related proposals are presented.

Key words: classification, failure consequences, reliability, risk, standards

\section{Razlikovanje pouzdanosti i ujednačenost rizika u propisima: kritički pregled i praktična ocjena}

\section{Sažetak}

Pouzdanost konstrukcija i infrastrukturnih objekata važan je dio graditeljske struke, te se u normama najčešće povezivala s razinom sigurnosti i sprječavanjem ljudskih žrtava. Posljednjih se, pak, godina pouzdanost sve više definira ekonomskim gubitcima, odnosno njihovom minimalizacijom. $U$ ovom se radu raspravlja o različitim principima definiranja pouzdanosti u suvremenim graditeljskim normama. Cilj je rada postizanje ujednačenih razina rizika za različite tipove konstrukcija. Dan je kritički osvrt na definicije i postupke modeliranja pouzdanosti u različitim propisima, s naglaskom na europsku normu Eurocode. Opisan je pristup klasifikaciji konstrukcija temeljen na posljedicama u slučaju njihova otkazivanja, koji nije toliko zastupljen u postupcima projektiranja. Praktične smjernice za takvu klasifikaciju te njeno uključivanje u proces projektiranja nužni su, što potvrđuju i slična istraživanja.

Ključne riječi: klasifikacija, posljedice otkazivanja, pouzdanost, rizik, propisi i norme 


\section{Introduction}

In parallel with the developments of performance-based design, risk and reliability methods have gained influence among the civil and structural engineering community. Risk-informed methodologies are widely used in connection with the design of new structures, or the assessment of existing ones, such as offshore structures, tunnels, dams, long-span bridges, or high-rise buildings. In addition, emphasis is given to the consideration of these methods for the development of modern standards. Within this background, the original focus is being extended from the individual component consideration (member design) to the overall performance of the entire structure (system design), or even, on a larger scale, to the network of which the structure is a part (system of systems).

Reliability of structures and infrastructures has always been a major issue in structural engineering. Reliability is a property of the structure that can be achieved or assured and is quantified by the probability of failure or the associated reliability index. A more complete parameter to approach reliability and to reach optimal decisions is risk, which is a combination of the probability of failure and the consequences of failure. In general, it is important to distinguish between various types of consequences, i.e. human losses, environmental damage, economic losses, and possibly the loss of cultural heritage value.

Structural standards have traditionally been concerned primarily with public safety in order to prevent loss of life or injury. This view has changed since the occurrence of recent catastrophic earthquake, flood and hurricane events towards the minimisation of total economic losses.

Structural codes, such as the Eurocodes, aim at delivering structures with an appropriate degree of reliability, while also taking into account economic concerns. Therefore, it is important to classify structures in terms of expected costs in case of structural failures in order to achieve uniform risk levels through reliability differentiation. Procedures and current codified criteria for risk and reliability differentiation inherent in standards, and especially in the currently valid version of the Eurocode EN 1990 [I], are reviewed in this contribution. It is shown that the classification of structures in the Eurocodes based on consequences of failure is an approach that has not yet been widely implemented in everyday design. A major reason is that the description of the consequences in the proposed classes is rather vague. Therefore, practical rules for the classification of structures and for implementation are still needed. One option is to classify structures based on their potential risk at the exposure level, as is the practice in the U.S.A. (see ASCE 7-I6 [2]). This option is discussed in this contribution. Differences between the European and the US approaches are highlighted, and a proposal for a simple classification of structures is provided. Conclusions for future developments are also given. 


\section{Definitions and Framework}

\subsection{Risk}

Risk analysis procedures have been well-established in recent decades and have been successfully applied in various industrial fields, such as the oil and transportation industries. In practice, a simple function relating the two constituents of risk is often used by multiplying the probability of failure $\mathrm{P}_{\mathrm{F}}$ by the consequences of failure $\mathrm{C}_{\mathrm{F}}$ in order to obtain the expected value of failure consequences:

$R=P_{F} C_{F}=E\left(C_{F}\right)$

The calculation of the failure probability is briefly discussed in Section 2.2. The consequences of failure may be expressed in monetary units or in terms of injuries and/or fatalities per failure event, or by some other indicator. One of the main steps in a risk analysis is the quantification of the consequences of failure in terms of 'cost of failure'. A systematic procedure to describe, and if possible quantify, such consequences is required. In general, the consequences resulting from failure of civil structures may be divided into a) human, including injuries and fatalities, b) economic, c) environmental and exceptionally d) the loss of cultural heritage value; for a summary see [3]. Note that according to the system under investigation, the same consequence can be direct or indirect. In order to combine the aforementioned types of consequences, a monetarization procedure can be used. Human consequences are thereby expressed using the Life Quality Index (LQI) concept and the Societal Willingness To Pay (SWTP) derived from and based on the LQI principle [4], [5]. The consequences of failure costs are combined with initial costs and maintenance costs in order to reach optimal decisions. The consequence assessment and description influences such decisions and should be performed at the most possible level of assessment. A number of difficulties are faced in the risk analysis procedures, such as:

- Calculation of small probabilities of failure frequently of the order of $10^{-5}$ per year or less, often based on limited data;

- Computation of consequences for the various considered scenarios based on models and input parameters frequently derived from previous experience;

- Combination of consequences to assess the total risk from its contributors (human, economic, environmental).

The results of a risk analysis are associated with uncertainties, which can be attributed to the relevance and significance of the databases, to the applied calculation models, and also to the possible assumptions, premises and expert judgements. Uncertainties can be dealt with by performing sensibility analyses, or better, by using probabilistic risk analysis techniques. In the latter procedure the probability of exceeding a specified level of risk (in term of annual losses) can be used.

In many practical studies, the societal risk of a project is considered and given in the form of a numerical F-N-curve. An F-N-curve shows the relationship between the 
annual frequency $\mathrm{F}$ of accidents with $\mathrm{N}$ or more fatalities. Upper and lower bound curves are recommended based on experience gained with similar projects/activities and the ALARP (As Low As Reasonably Practical) acceptability criterion is obtained as the domain between the aforementioned limits [3].The upper limit represents the risk that can be tolerated in any circumstances, while the risk below the lower limit is of no practical interest. Such acceptability curves have been developed for various industrial fields, including the chemical and the transportation industries. The societal human safety criterion can be also similarly represented by the following formula relating acceptable probability of failure $P_{F}$ to number of fatalities $N_{f}[6]$ :

$P_{F} \leq A \cdot N_{f}^{-m}$

where $A$ and $m$ are constants usually derived from statistical observations of natural and man-made hazards. From statistical observations the constants $A$ and $m$ in Eq. (2) vary widely depending on the type of hazard and the type of technical activity. It has been proposed to set the constants such that the curve envelops the curves for most natural hazards and some more common man-made hazards from below. For acceptable risks of structural failure, the constant would be around $A=10^{-6}$ and for marginally acceptable risks $A=10^{-4}$; note that $\mathrm{m}=\mathrm{I}$ represents risk-neutral curves, $\mathrm{m}>$ I describes curves with risk aversion and $\mathrm{m}<\mathrm{I}$ curves with risk proneness [6]. The aforementioned criteria can be represented by a so-called risk acceptability matrix when detailed data are unavailable [3]. For that purpose, qualitative hazard probability levels are defined as well as qualitative hazard severity levels of failure consequences. The hazard probability levels and the hazard severity levels are then combined to generate a risk classification matrix. The described procedures are related to group risk; however, the individual risk must also be considered [6]. No individual (or group of individuals) involved in a particular activity can be exposed to an unacceptable risk; a typical value is $10^{-6}$ per year. If a worker or a member of the public is found to be exposed to excessive risk, either safety measures are adopted regardless of the cost-benefit effectiveness, or premiums are offered.The latter is the case of highly exposed workers, including members of safety corps, soldiers, miners, or offshore workers. Besides human safety, economic risk plays an important role in decision-making. Economic losses are:

- direct consequences related, for example, to the repair of initial damage; replacement of structure and equipment

- indirect consequences such as loss of production, temporary relocation, rescue costs, or loss of reputation.

A similar relationship to human risk can be derived by substituting the number of fatalities with the economic damage in monetary value. Finally, environmental consequences are a third contributor to the consequences and can be presented in terms of permanent or long-term damage to terrestrial, freshwater, marine habitats and groundwater reservoir.The combination of the three basic types of consequences has been analysed in [7]. 


\subsection{Reliability}

Basic reliability measures include probability of failure and reliability index, as shown for example in [5], [6]. The probability of structural failure $p_{F}$ can be generally defined as the probability of exceeding a given limit state of structural member such as bending or shear resistance. It is noted that the exceedance of the limit state is related to the failure of a component of a structure. The structure is represented by a system of components and might survive when a component (column, slab, beam, etc.) fails. System reliability methodologies can be applied to compute the reliability of a structural system. Instead of the failure probability $P_{f}$, the reliability index $\beta$ is used as an equivalent measure to $P_{F}$ :

$\mathrm{P}_{\mathrm{F}}=\Phi(-\beta) \approx 10^{-\beta}$

where $\Phi()$ = distribution function of the standardized normal distribution. Reliability acceptance criteria can be defined in terms of the target and acceptable failure probability $\mathrm{P}_{\mathrm{T}}$ or the target and acceptable reliability index $\beta_{\mathrm{T}}$ These quantities are recommended as reasonable minimum requirements and it is emphasized that $\mathrm{P}_{T}$ and $\beta_{\mathrm{T}}$ are formal conventional quantities only and may not correspond to actual frequency of failures. In reliability analysis of a structure it is generally required that:

$\mathrm{P}_{\mathrm{F}} \leq \mathrm{P}_{\mathrm{T}}$

or equivalently in terms of reliability index:

$\beta \geq \beta_{\mathrm{T}}$

where $\mathrm{P}_{\mathrm{T}}$ is the specified design (target) failure probability corresponding to the target reliability index $\beta_{T}$ The target reliability is different for each structure depending upon the potential consequences of failure, thus reflecting the desired uniform risk reflected through risk acceptance criteria. Therefore, it is appropriate to classify structures with respect to the consequences of failure and to define related target reliability levels [5], [6].

\section{Implementation in standards}

\subsection{European approach in the Eurocodes [1]}

Three consequence-class categories are defined in the present version of the Eurocodes as shown in Table I for the case of buildings. The classification is basically performed at the structures level and respective examples of buildings and civil engineering works are given. However, it is noted in [I] that, depending on the structural form and decisions made during design, particular members of the 
structure may be designated in the same, higher or lower consequences class than for the entire structure.

Table I. Definition of consequences classes CC in the Eurocodes [I]

\begin{tabular}{|c|c|c|}
\hline CC & Description & $\begin{array}{c}\text { Examples of buildings and civil engi- } \\
\text { neering works }\end{array}$ \\
\hline $\mathrm{CCl}$ & $\begin{array}{l}\text { Low consequence for loss of human life, } \\
\text { and economic, social or environmental } \\
\text { consequences small or negligible }\end{array}$ & $\begin{array}{c}\text { Agricultural buildings where people do } \\
\text { not normally enter (e.g. storage buildings), } \\
\text { greenhouses }\end{array}$ \\
\hline $\mathrm{CC} 2$ & $\begin{array}{l}\text { Medium consequence for loss of human } \\
\text { life, economic, social or environmental } \\
\text { consequences considerable }\end{array}$ & $\begin{array}{l}\text { Residential and office buildings, public } \\
\text { buildings where consequences of failure are } \\
\text { medium (e.g. an office building) }\end{array}$ \\
\hline $\mathrm{CC} 3$ & $\begin{array}{c}\text { High consequence for loss of human life, } \\
\text { or economic, social or environmental } \\
\text { consequences very large }\end{array}$ & $\begin{array}{l}\text { Grandstands, public buildings where conse- } \\
\text { quences of failure are high (e.g. a concert hall) }\end{array}$ \\
\hline
\end{tabular}

At first sight, the classification of a building into one of the consequence classes in Table I looks simple and reasonable; however, further inspection reveals that quantitative parameters are missing for an appropriate classification. In the EN I99|I-7 on accidental actions, and especially in some national regulations such as those in England and Wales, more detailed guidance on the classification of buildings is provided and discussed, as shown for example in [8]. The number of storeys, the floor area and the building occupancy type are thereby principal determinants of the building consequence class. The number of persons at risk is thus indirectly considered by taking building occupancy rates into account.

In the case of bridges, the draft of Annex A2 of EN 1990 from April 2019 provides more detailed classification with more examples:

- $\mathrm{CCl}$ :Short-span structures such as culverts, short river crossings

- CC2: Bridges not in other consequence classes

- CC3a: Railway bridges, bridges over or under railways or major roads

- CC3b (higher consequences where an increased level of reliability is required): when specified by the relevant authority or agreed for a specific project by the relevant parties

Other aspects that could be taken into account in the classification of bridges include the network importance reflected through traffic volume, the potential consequences through span length and the static system (redundancy), or the possibility of detours for personal and freight traffic. The consequence classes are related to reliability classes RC for which target reliability in terms of $\beta_{\mathrm{T}}$ are given, as shown in Table 2. If, for example, the failure consequences in terms of human fatalities are for a $\mathrm{CCl}$ structure $\mathrm{C}_{F}=\mathrm{I}$ fatality, for a $\mathrm{CC} 2$ structure $\mathrm{C}_{\mathrm{F}}=10$ fatalities, and for a $\mathrm{CC} 3$ structure $C_{F}=100$ fatalities, then for all three classes the acceptable expected failure consequences are $10^{-5}$ fatalities per year, i.e. the risk level is uniform. 
The reliability differentiation in the Eurocodes is implemented through multiplication factors for the actions as shown in Table 3, i.e. through the implementation in the semi-probabilistic format. It is of interest to mention that this procedure of Annex C in the present version of EN 1990 is informative and not normative. For example, in Germany it is not allowed to use the reliability class differentiation procedures [9].

Table 2.Target reliability (one-year reference period) in the Eurocodes

\begin{tabular}{|c|c|}
\hline Reliability class & \multicolumn{2}{|c|}{ Target reliability $\beta_{\mathrm{T}}$} \\
\hline RC I & $4.2 \quad\left(\mathrm{P}_{\mathrm{T}} \approx 10^{-5}\right)$ \\
\hline RC 2 & $4.7 \quad\left(\mathrm{P}_{\mathrm{T}} \approx 10^{-6}\right)$ \\
\hline RC 3 & $5.2 \quad\left(\mathrm{P}_{\mathrm{T}} \approx 10^{-7}\right)$ \\
\hline
\end{tabular}

Table 3. $\mathbf{k}$ factor for unfavourable actions according to [I]

\begin{tabular}{|c|c|c|c|}
\hline k factor for actions & \multicolumn{3}{|c|}{ Reliability class } \\
\hline & $\mathrm{RCl}$ & $\mathrm{RC2}$ & $\mathrm{RC3}$ \\
\hline$k$ & 0.9 & 1.0 & $\mathrm{I} . \mathrm{I}$ \\
\hline
\end{tabular}

A $10 \%$ decrease of the partial factors for unfavourable actions can be observed in the case of $\mathrm{RCl}$ members and a 10\% increase of the partial factors for actions in the case of RC3 members, independent of the type of action, compared to RC2 members. The $k$ factor theoretically depends on the statistical parameters of the action, i.e. distribution type and coefficient of variation and thus i) for environmental actions should be site specific and ii) the relative difference should be higher in case of variable actions compared to permanent actions. In fact, the increase/decrease is larger than $10 \%$ in case of variable actions with extreme type I distribution and coefficient of variation larger than 0.10 and lower than $5 \%$ in the case of permanent actions with normal distribution and coefficient of variation lower than 0.10 . This is illustrated in Figure I for the permanent action $G$ (dead load) and the variable action $W$ (wind pressure depending on wind velocity). The corresponding theoretical values obtained by the design value method (DVM) [5] and the $k$ factors specified in the Eurocodes are thereby highlighted. While the Eurocode $k$-factors seem to be nonconservative for dominating wind pressure, and over-conservative for dominating permanent actions, they may be well optimised for the combinations of similarly important permanent and wind actions. 


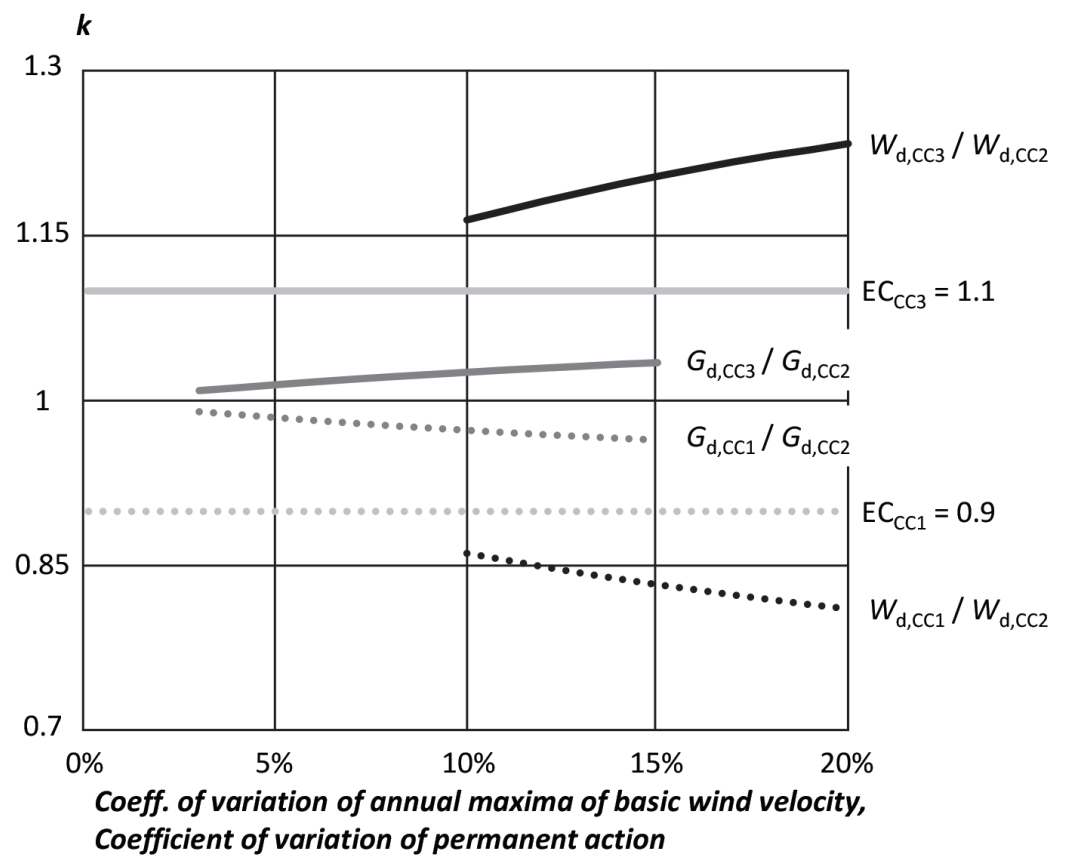

Figure I. $k$-factor

In addition, the impact of the $k$ factors given in Table 3 does not have a linear proportional influence to the construction costs since a) construction costs include constructional arrangements such as reinforcement details, b) designers frequently select dimensions on the safe side and verify them at the detailed design stage and c) serviceability requirements may govern the dimensions of some members. A typical reinforced concrete basement made of C20/25 part of a larger structure divided by joints has been selected to investigate these aspects. The ground plan including the various positions for the structural analysis is shown in Figure 2. The system typical for many constructions is symmetric and the designer has selected all columns and related single foundations to have one position i.e. that of the column $\mathrm{Cl}$ and related foundation $\mathrm{FI}$ with the maximum loads, shown in Fig. 2 together with the related tributary area. In addition, reinforcement stirrups in columns, connection reinforcement between walls and slab, minimum depth of foundation, and choice of slab thickness at the preliminary design phase, lead to the total difference between construction costs much lower than $5 \%$ between the consequence class categories. The loads consist of permanent (dead) load and variable (live) load. Two different cases due to usage types and related characteristic live loads were considered: a) $q_{k}=20 \mathrm{kN} / \mathrm{m}^{2}$ due to use as a storage hall for heavy materials and machines b) $q_{k}=2 \mathrm{kN} / \mathrm{m}^{2}$ due to use as an office area. In each case three subcases related to an increase or decrease of the loads by $10 \%$ associated to the $\mathrm{k}$-factors in Table 3 were defined. In case a) the slab thickness was selected as $24 \mathrm{~cm}$ and, in case b), 
as $20 \mathrm{~cm}$. The beam dimensions were selected to fulfil the Eurocode requirements. The construction costs were calculated first without considering costs of subsidiary structural reinforcement. The cost difference related to the $k$-factors was $-4 \%(k=0.9$, $\mathrm{RCI})$ and $+5 \%(k=\mathrm{I} . \mathrm{I}, \mathrm{RC} 3)$ compared to $k=1.0(\mathrm{RC2})$ for case a). In case b) this difference resulted $-3 \%(k=0.9, R C I)$ and $+3 \%(k=1 . I, R C 3)$ compared to $k=1.0$ (RC2). In addition, reinforcement stirrups in columns, connection reinforcement between walls and slab foundation and columns, minimum depth of foundation etc., lead to a reduction of the total difference between construction costs lower than $3 \%$ between the consequence class categories. Costs related to site facilities and excavations will further reduce the above cost ratios.

\subsection{U.S. approach}

A separate classification for buildings and bridges has been implemented for design purposes in the U.S.A. The 2017 edition of ASCE 7, Minimum Design Loads for Building and Other Structures [2], has followed as a major step towards risk and reliability differentiation:

- Risk categorization

- (Inherent) acceptable reliability for load conditions

- Respective importance factors for load conditions

- Hazard maps for risk informed performance based engineering (wind, earthquake)

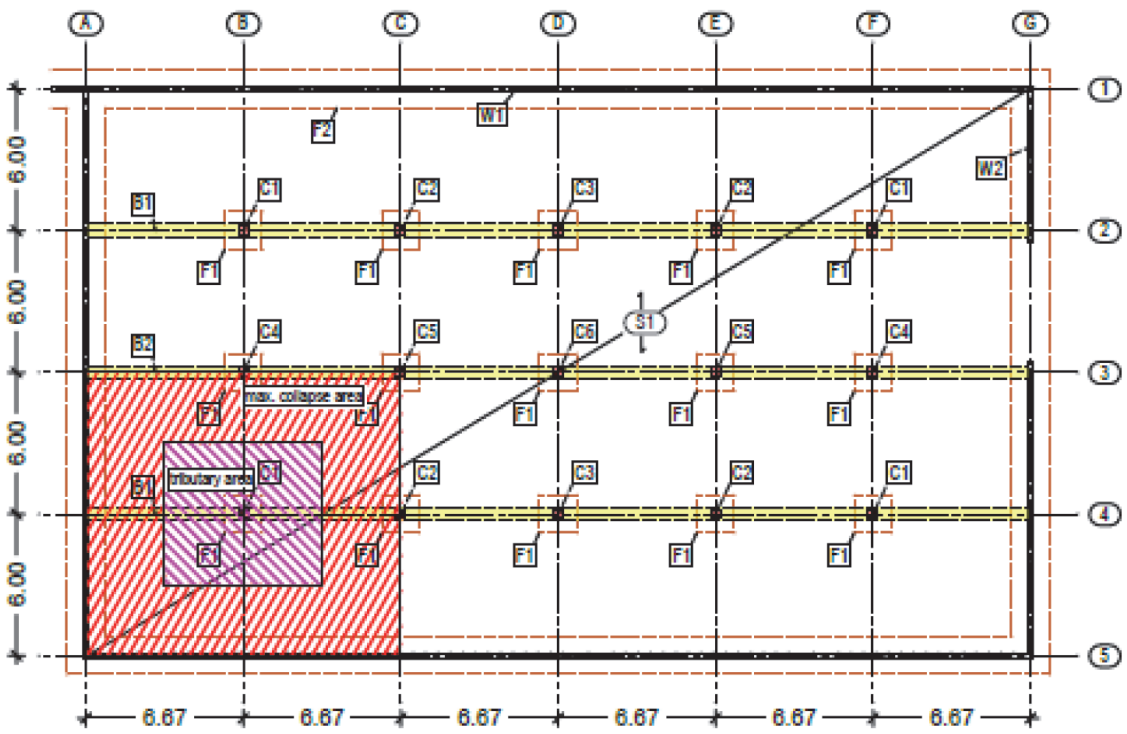

Figure 2. Example study S: slab, B: beam, C: column, FI: single foundation, F2: strip foundation, $W$ : wall (dimensions in $\mathrm{m}$ ) 
Buildings and other structures are classified into four risk categories, based on the risk to human life, health, and welfare associated with their failure by nature of their occupancy or use. The basis for classification is the number of persons at risk (Figure 3). It is noted that persons (lives) at risk from a structural failure include persons who may be outside the structure but affected in the case of failure of the structure. When considering the population at risk, attention should also be given to longer term risks to life than those created during a structural failure. Therefore, higher reliability levels are required, not only for buildings and structures of higher risk category with high levels of occupancy, but also for structures with essential function (hospitals, fire stations, etc.) for the communities. Figure 3 also includes the qualitative relation between the number of persons at risk and the number of fatalities as experienced in structural collapses.

It is emphasised that neither ASCE nor EN 1990 give quantitative limits for numbers of persons at risk or number of fatalities. Figure 3 also indicates the number of fatalities deemed to be associated with the EN 1990 consequence classes, leading approximately to a uniform risk when considering the EN 1990 target levels. These indications are based on the authors' judgement, taking into account the assumptions by Trbojevic [10], the database of structural collapses analysed by Hingorani et al. [I I], and the comparison of CCs with the ASCE Risk Categories.

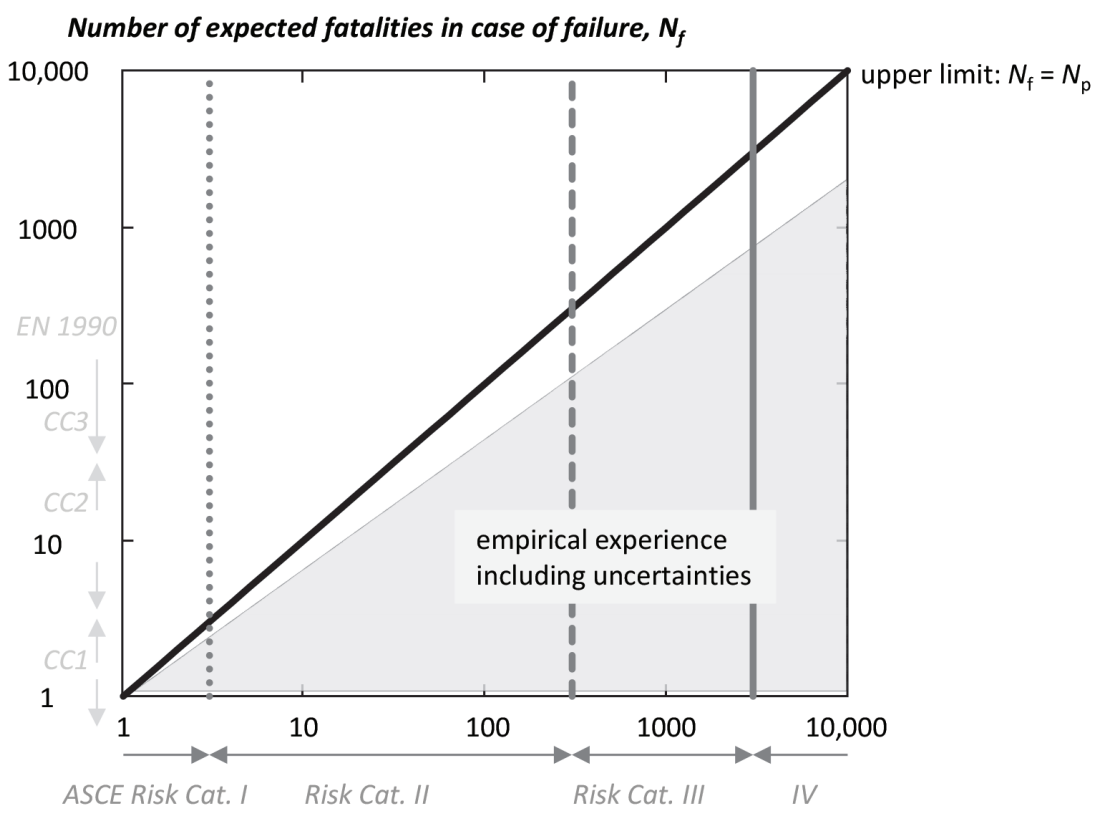

Number of persons at risk, $N_{p}$

Figure 3.Approximate relationship between ASCE risk categories, number of persons at risk [2] and number of fatalities in a qualitative manner, including indication of the consequence classes (CC) in EN 1990 
The elimination of the specific examples of buildings that fall into each category has the benefit of eliminating the potential for conflict between the standard and locally adopted codes, and also of providing individual communities and development teams with flexibility to interpret acceptable risk for individual projects [2]. Where buildings or other structures are divided into portions with independent structural systems, it should be permitted to determine the classification for each portion independently [2]. The target failure probabilities and the associated derived target annual reliability indices are reported in Table 4. They vary by the risk category and also depend on the type of failure. The values have been developed by a number of expert groups and have also been confirmed through professional practice. In addition, it is noted that the standard ASCE 7-I6 does not implement the same target values in the case of earthquake or tsunami action, as it is not presently economically viable, and therefore higher target failure probabilities are accepted for these accidental situations.

Table 4. Target annual inherent failure probability $\mathrm{p}_{\mathrm{T}}$ and target reliability index $\beta_{\mathrm{T}}$ (for load conditions that do not include earthquake, tsunami and extraordinary effects)

\begin{tabular}{|c|c|c|c|c|}
\hline Risk Category & I & II & III & IV \\
\hline $\begin{array}{c}\text { Failure is not sudden and without wide- } \\
\text { spread progression of damage }\end{array}$ & $\begin{array}{c}1.25 \times 10^{-4} \\
3.66\end{array}$ & $\begin{array}{c}3.0 \times 10^{-5} \\
4.0 \mathrm{I}\end{array}$ & $\begin{array}{c}1.5 \times 10^{-5} \\
4.21\end{array}$ & $\begin{array}{c}5.0 \times 10^{-6} \\
4.42\end{array}$ \\
\hline $\begin{array}{c}\text { Failure is either sudden or without wide- } \\
\text { spread progression of damage }\end{array}$ & $\begin{array}{c}3.0 \times 10^{-5} \\
4.01\end{array}$ & $\begin{array}{c}5.0 \times 10^{-6} \\
4.42\end{array}$ & $\begin{array}{c}2.0 \times 10^{-6} \\
4.61\end{array}$ & $\begin{array}{c}7.0 \times 10^{-7} \\
4.83\end{array}$ \\
\hline $\begin{array}{c}\text { Failure is sudden and results in widespread } \\
\text { progression of damage }\end{array}$ & $\begin{array}{c}5.0 \times 10^{-6} \\
4.42\end{array}$ & $\begin{array}{c}7.0 \times 10^{-7} \\
4.83\end{array}$ & $\begin{array}{c}2.5 \times 0^{-7} \\
5.03\end{array}$ & $\begin{array}{c}1.0 \times 10^{-7} \\
5.20\end{array}$ \\
\hline \multicolumn{2}{|c|}{} & & &
\end{tabular}

The influence of the risk categories in design is implemented through importance factors for the actions, i.e. a procedure similar to the one of the Eurocodes is used. However, the factors apply to environmental actions only. They differ according to statistical characteristics of the environmental loads and the manner in which the structure responds to the loads. Maps for different return periods T corresponding to each risk category are provided for wind and earthquake action, aiming at a uniform risk.

Figure 4 shows a comparison between the scaled design values for wind action in the Eurocodes and in the design philosophy by ASCE, reflected in the different return periods $T$ for each category as a function of the coefficient of variation of the wind velocity (relative to the characteristic Eurocode wind pressure). While the values are independent from the variability of wind velocity in the case of the Eurocodes since fixed $k$ factors and partial factors are used, the approach based on return period leads to a more uniform risk, especially if the variability of wind velocity is considered in order to represent regional variations. 
In the case of bridges, the AASHTO standard [12] provides a useful classification of road bridges into:

- essential bridges

- critical bridges

- other bridges

for which differentiated design parameters are provided. The basic classification parameters are span length, detour length, and traffic importance. The consequences of failure are therefore implicitly taken into consideration.

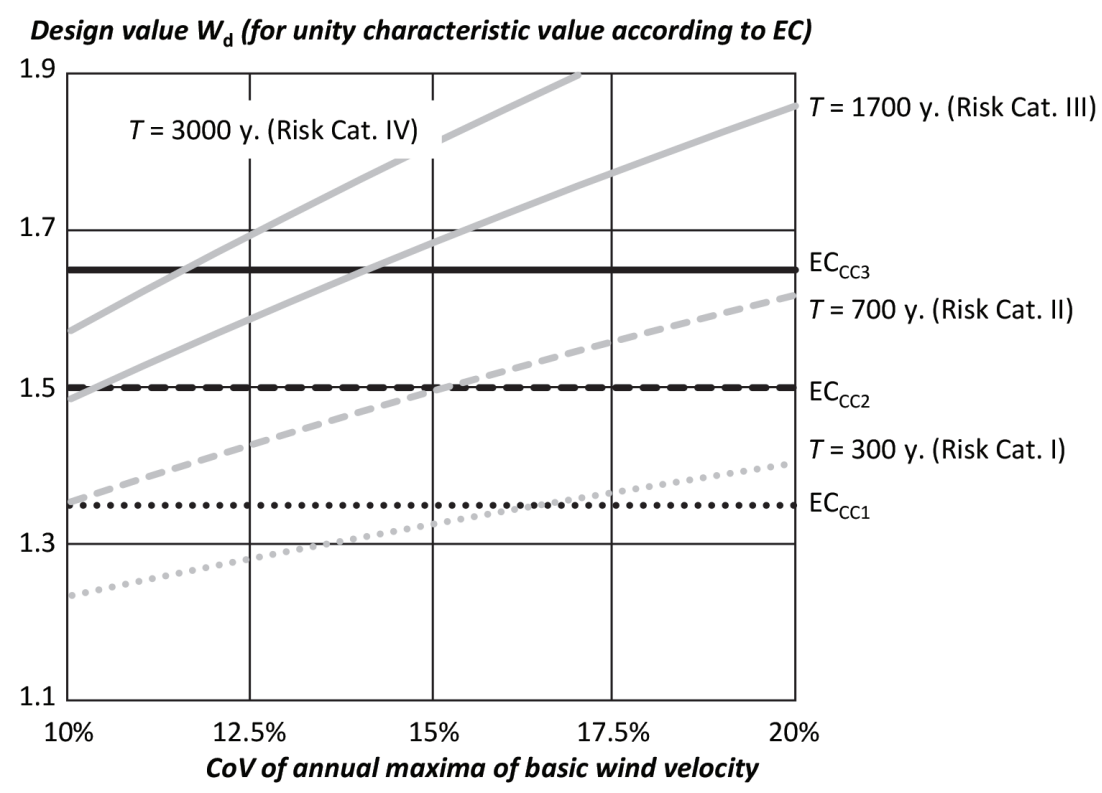

Figure 4. Design values of wind pressure according to the Eurocodes and related to the return periods $T$ as a function of the coefficient of variation of wind velocity (relative to the characteristic Eurocode wind pressure)

\subsection{JCSS recommendations [6], [13]}

A classification scheme of structures is used by the Joint Committee on Structural Safety (JCSS) in order to define target reliabilities. The target values for the ultimate limit states related to failure of structural members are presented in Table 5. The values are based on the study by Rackwitz [14] and correspond to individual structural elements for a one-year reference period, and reflect as well code calibration experience and the aforementioned cost-benefit considerations. These values shall be considered in reliability analyses in association with the stochastic models for the influencing variables as described in the JCSS probabilistic model code [13]. The values have also been reported in ISO 2394 [5] where, however, five consequence classes are proposed. 
The JCSS target values depend not only on the consequences of failure, but also on the relative costs of safety measures, for which it is more difficult to provide quantitative recommendations. However, they depend on their effectiveness to increase reliability. In addition, the following important aspects are provided by the JCSS [6], [13]:

a) The consequences of failure are quantified by a ratio $\rho$ representing the ratio between the total failure costs $\mathrm{C}_{0}+\mathrm{C}_{1}(\mathrm{P})+\mathrm{H}$ and the construction costs $\mathrm{C}_{0}+$ $C_{1}(p)$. The construction costs have a fixed part $C_{0}$ and costs $C_{1}(p)$ depending on the selected design parameter $\mathrm{p}$. The factor $\mathrm{H}$ represents the direct failure costs including direct physical damage, cost of demolition and removal, but also cost of human life and injury [14]. For example, in the case of large consequences $\rho$ ranges between 5 and 10. Further discussion can be found in [15]; it is noted that higher $\rho$-values are realistic in case of member failure as discussed in Section 4.I.

b) In case of structures with extreme failure consequences i.e. $\rho>10$ the target values shall be defined based on risk-benefit studies.

c) The values given relate to the structural system or in approximation to the dominant failure mode or structural component dominating system failure. Therefore, structures with multiple, equally important failure modes should be designed for a higher level of reliability.

d) For existing structures, the costs of achieving a higher reliability level are usually high compared to structures under design. For this reason, the target level for existing structures should usually be lower.

Table 5. Target reliability indices $\beta_{\mathrm{T}}$ (and associated target failure rates) related to one-year reference period and ultimate limit states [5], [I3]

\begin{tabular}{|c|c|c|c|}
\hline $\begin{array}{c}\text { Relative cost of } \\
\text { safety measure }\end{array}$ & $\begin{array}{c}\text { Minor } \\
\text { consequences } \\
\rho \leq \mathbf{2}\end{array}$ & $\begin{array}{c}\text { Moderate conse- } \\
\text { quences } \mathbf{2}<\rho \leq \mathbf{5}\end{array}$ & $\begin{array}{c}\text { Large } \\
\text { Consequences } \\
\mathbf{5}<\rho \leq 10\end{array}$ \\
\hline Large (A) & $3.1\left(\mathrm{P}_{\mathrm{T}} \approx 10^{-3}\right)$ & $3.3\left(\mathrm{P}_{\mathrm{T}} \approx 5 \times 10^{-4}\right)$ & $3.7\left(\mathrm{P}_{\mathrm{T}} \approx 10^{-4}\right)$ \\
\hline Normal (B) & $3.7\left(\mathrm{P}_{\mathrm{T}} \approx 10^{-4}\right)$ & $4.2\left(\mathrm{P}_{\mathrm{T}} \approx 10^{-5}\right)$ & $4.4\left(\mathrm{P}_{\mathrm{T}} \approx 5 \times 10^{-6}\right)$ \\
\hline Small (C) & $4.2\left(\mathrm{P}_{\mathrm{T}} \approx 10^{-5}\right)$ & $4.4\left(\mathrm{P}_{\mathrm{T}} \approx 5 \times 10^{-5}\right)$ & $4.7\left(\mathrm{P}_{\mathrm{T}} \approx 10^{-6}\right)$ \\
\hline
\end{tabular}

\section{Discussion}

\subsection{Member versus system failure}

Since designers are mainly applying safety formats at a component (structural member) level, the definition of targets for members and associated limit states is preferred. In fact, the Eurocodes [I] have proposed target reliabilities for safety checking at localised limit states representing in practice member failure. However, the members are classified in terms of consequences of failure into reliability classes 
which correspond practically to the defined consequences classes (CC); when a structure is classified into a CC their members are designed in most cases for the same target safety level. Although a different classification of different members (and failure modes) is allowed, this is hardly ever used in practice. Consequently, the safety class differentiation concept has not been implemented in everyday design by many European countries, basically because the classification procedure is very vague and experienced designers know the critical members of the structure and often increase their reliability. Also, one should bear in mind that structural components designed by the code will usually have a sufficient reliability against component failure beyond these local failure conditions due to:

a) cross section or internal redundancy;

b) possible alternative load paths and formation of hinges.

It follows that in many cases the failure of single members will have significantly lower consequences compared to the failure of the main part of the structure (system failure). Therefore, target annual failure probabilities are different, for example in the case of sudden widespread failure as given in [2]. It appears important to distinguish between member failure and structural collapse when proposing target safety levels. When deriving target safety levels by considering failures resulting in large collapsed areas and many fatalities, it is obvious that these levels are more related to system failure, i.e. global failure or failure of the main part of the structure. For bridges the difference between the target member reliability and the target structure system reliability $\Delta \beta_{\mathrm{T}}$ is of the order of 0.5 according to the single path or multiply path failure [16]. A difference of the order of 0.4 reflects in practice the fact that in the case of system failure (main part of the structure), one expects an order of magnitude more fatalities compared to a local (member/element) failure (for example 10 instead of I) based on considerations regarding target safety dependence on the number of fatalities provided in many literature sources [17], [18].

The Eurocodes define the target reliability at a component level. The annual value for CC2 is $\beta_{\mathrm{T}}=4.7$ and larger compared to the value given by the JCSS, $\beta_{\mathrm{T}}=4.2$. However, the JCSS suggests that structures with multiple, equally important failure modes should be designed for a higher level of reliability. This is the case for many structures in practice - such as the symmetric structure shown in Figure 2 - and an increase of $\Delta \beta_{\mathrm{T}}=0.5$ is recommended here, resulting in the same target reliability as the Eurocodes. It is noted that similar values are given in ASCE [2]; the target reliabilities discussed herein are, though, broadly compatible. For practicing engineers, it is easier to perform verifications at the component level. However, the overall performance of the structure should be checked for the performance objectives in the case of natural or man-made hazards and associated extreme loadings. This requirement can be implemented by considering the system behaviour of the structure (indirectly through the failure consequences) in the selection of an appropriate target member safety level.

Finally, an interesting discussion of the consequence ratio is presented in [15] where $\rho$ is derived as the ratio between the total consequences i.e. direct (member failure) 
and indirect (system failure given member failure) and the direct consequences. However, the direct consequences in case of member failure are approximated by the replacement costs of the failed element, which in practice is frequently an underestimation; in most cases site inspection, additional analyses, occupancy restrictions, and special techniques are required, and these are associated with much higher costs compared to original construction costs of the failed member.

\subsection{Exposure versus consequence level}

While in the European and the JCSS approach the classification of structures is performed explicitly at the failure consequences level, in the US approach the exposure level associated with the human risk, i.e. the number of persons at risk, is considered. The consequences of failure are thus implicitly taken into account.

One should bear in mind that human consequences are expressed in terms of a number of fatalities $N_{f}$ which depend basically on:

- Number of persons at risk

- Probability of exposure (depending on time/date of failure)

- Possible warning factor and failure characteristics

- Probability of self-rescue and probability of rescue by third parties.

The assessment of consequences is related to uncertain parameters which are partially independent of the structure; for instance, the efficiency of rescue services. For practicing engineers, and especially at the design stage, it is difficult to estimate the consequences in a quantitative way; for example, in terms of the consequence ratio $\rho$. Similarly, a vague classification as in the Eurocodes does not support the wide use of the reliability differentiation procedure. In contrast, a classification based on parameters that can be easily determined at the design stage, such as the population at risk, facilitates the implementation of the classification concept. Even if this number cannot be directly assessed, it can be indirectly obtained from the gross floor area and the type of use of a building. For example, it is known that in Germany the average area per occupant in a residential building is approximately $30 \mathrm{~m}^{2}$, while it is approximately $10 \mathrm{~m}^{2}$ in an office building. The number of occupants in a building can be obtained based on the gross floor area. In addition, the number of persons at risk related to essential structures can be estimated from the characteristics and population of the community they serve.

An approach for the estimation of human consequences has been presented in [19] based on recorded collapse data and respective statistical analyses. Thereby the number of fatalities can be obtained from the number of persons present in the collapse area and also from the collapsed area itself. The collapse area as illustrated here in Figure 2 reflects the importance of the key-members and shall be kept by appropriate design below given values. However, the procedure does not consider other persons affected that are not present in the building.

Considerations similar to the aforementioned discussed for buildings are also valid for bridges. Significant factors having an impact on the consequences of failure have 
been analysed in [20]. The main influencing parameters are span length, traffic volume in terms of AADT (Annual Average Daily Traffic) in vehicles per day and detour length. Such parameters are available and can be implemented in practice.

\subsection{Existing versus new structures}

The reliability assessment of existing structures differs from new structures in a number of aspects, including lower target reliability levels since safety measures usually involve greater increment of costs for existing structures than for new structures, or reduced working life compared to the design working life of 50-100 years assumed for new structures. Therefore, lower values are suggested by the JCSS [13] since the relative cost of achieving a higher reliability level is usually higher compared to structures under design. The reduction can be assessed by implementing the values associated to the higher category of relative cost of safety. A practical reduction of the target value by 0.5 for existing structures compared to new designs has been recommended in [2I], [23]. Also, a minimum target reliability, below which the structure should be upgraded, is proposed in [22], [23].

Regarding the classification of structures, the same classes shall be used for consistency reasons. However, one may apply more detailed models that are available for the assessment of consequences, since in many cases particular members are considered in the reassessment phase. By applying more refined procedures, different members in the same structure can be assigned to different consequence classes.

\section{Recommendations}

Based on the above discussion, it is here proposed to apply classification schemes with quantitative parameters related to risk exposure. Consequences are considered implicitly and do not need to be assessed by practicing engineers at the design phase. By considering the standards review, practical implications, and analytical results from the literature, the proposed classification is given in Table 6 for buildings and in Table 7 for bridges. In Table 6, all persons at risk affected by structural collapse shall be considered, rather than only the occupants of the building. Once the structure is classified, its members are designed for the same reliability level based on modified partial factors for actions. Such a procedure can easily be applied and represents for many countries a progress towards uniform risk. Different target reliabilities within the same structure may be considered in the assessment of an existing structure, since more sophisticated methods are usually applied in such cases. 
Table 6. Consequence classification of buildings and other structures

\begin{tabular}{|c|c|c|}
\hline $\begin{array}{c}\text { Consequence } \\
\text { Class }\end{array}$ & $\begin{array}{c}\text { Number of persons } \\
\text { at risk } \mathbf{N}\end{array}$ & Description \\
\hline $\mathrm{CCl}$ & $\mathrm{N}<10$ & single occupancy houses, agricultural structures \\
\hline $\mathrm{CC} 2$ & $10 \leq N<1000$ & all other buildings/structures \\
\hline $\mathrm{CC} 3$ & $N \geq 1000$ & $\begin{array}{c}\text { structures with } N \geq 1000 \text { (permanent use), grand- } \\
\text { stands with more than } 5000 \text { persons, structures } \\
\text { utilised in important industries, resilience critical } \\
\text { structures serving communities with more than } \\
5000 \text { persons }\end{array}$ \\
\hline
\end{tabular}

Table 7. Consequence classification of bridges

\begin{tabular}{|c|c|}
\hline $\begin{array}{c}\text { Consequence } \\
\text { Class }\end{array}$ & Description \\
\hline $\mathrm{CCl}$ & $\begin{array}{l}\text { bridges for pedestrian or cycle use only with traffic less than } 50 \text { persons per } \\
\text { hour, road bridges in rural areas with AADT } \leq 5000 * \text { vehicles per day or a span } \\
\text { length shorter than } 10 \mathrm{~m}\end{array}$ \\
\hline CC2 & all other bridges \\
\hline CC3 & $\begin{array}{l}\text { long-span bridges for pedestrian or cycle use, road bridges with either AADT } \\
\geq 50,000 * \text { vehicles per day or no possibility of detour (detour length greater } \\
\text { than } 25 \mathrm{~km} \text { in rural areas and greater than } 10 \mathrm{~km} \text { in urban areas) or span length } \\
\text { greater than } 100 \mathrm{~m} \text {; railway bridges on transnational, national and main regional } \\
\text { lines and special railway bridges (metro and tram bridges, bridges in important } \\
\text { industrial plants) }\end{array}$ \\
\hline
\end{tabular}

\section{Summary and conclusions}

Procedures and current codified criteria for reliability differentiation inherent in standards and especially in the Eurocodes [I] and in the ASCE code [2] are discussed in this contribution. The risk and reliability analysis represents a highly specialized field, and the practicing engineers expect guidelines and rules that are at the same time adequately simple, transparent, and realistic. It is stated that the classification of structures based on consequences of failure is an approach that has not yet been implemented in everyday design in many European countries. A major reason is that the description of the consequences in the proposed classes is rather vague and inevitably subjective. Therefore, practical rules for the classification of structures and implementation are presented in this contribution. These rules are supported by limit values, but are also flexible enough to allow the project specific interpretation of the acceptable. 
The following conclusions can be drawn:

- The classification can be based implicitly on the exposure level or, explicitly, on the consequence level. The implementation needs quantitative parameters for the practical distinction between the categories that can be more easily defined and applied by designers at the exposure level.

- Reliability differentiation aims at uniform risk for the different categories and can be applied by adjustment factors, or by different return periods in the case of variable environmental actions.

- Target reliability levels for structural members presented herein are compatible. Target reliabilities for system failure are, however, also needed. Both can vary depending on the type of hazard considered due to the related costs to increase safety.

- Different target reliabilities within the same structure may be considered in the assessment of an existing structure.

\section{Acknowledgements}

This work has been supported by the Regensburg Center of Energy and Resources (RCER) of OTH Regensburg, by the Technology- and Science Network Oberpfalz (TWO), by the Ministry of Education, Youth and Sports of the Czech Republic under Grant LTTI8003, and by the Technological Agency of the Czech Republic under Grant TE01020068.

\section{References}

[1] EN 1990, Eurocode - Basis of Structural Design, European Committee for Standardization, 2002.

[2] American Society of Civil Engineers (ASCE), Minimum Design Loads for Buildings and other Structures, ASCE SEI 7-16, Reston,VA, USA, 2017.

[3] Diamantidis, D.: A critical view on environmental and human risk acceptance criteria, International Journal of Environmental Science and Development, 8 (2017), pp. $62-68$.

[4] Faber, M.H., Stewart, M.G.: Risk assessment for civil engineering facilities: critical overview and discussion, Reliability engineering \& system safety 80 (2008) 2, pp. 173- 184.

[5] International Organization for Standardization, ISO 2394:20I5 - General principles on reliability for structures, 2015.

[6] Joint Committee on Structural Safety (JCSS) (edited by D. Diamantidis), Probabilistic Assessment of Existing Structures, RILEM Publications S.A.R.L., 200I.

[7] Diamantidis, D., Holický, M., Sýkora, M.: Target Reliability Levels Based on Societal, Economic and Environmental Consequences of Structural Failure, 12th International Conference on Structural Safety \& Reliability, ICOSSAR.Vienna, Austria, 2017.

[8] Brooker, O.: How to design concrete buildings to satisfy disproportionate collapse requirements, The Concrete Centre, Surrey, UK, 2008. 
[9] Muster Liste der Bautechnischen Bestimmungen, Juni 2015. www.dibt.de/de/wir-bieten/technischebaubestimmungen, 25.04.2019.

[10] Trbojevic,V.M.: Another look at risk and structural reliability criteria, Structural safety 3 I (2009), pp. $245-250$.

[II] Hingorani, R.,Tanner, P., Prieto, M., Lara, C.: Consequence classes and associated models for predicting loss of life in collapse of building structures (under review), Structural Safety (2019).

[12] AASHTO.AASHTO LRFD Bridge Design Specifications, Eighth Edition, LRFD-8.American Association of State Highway and Transportation Officials, Washington DC, USA, 2017.

[13] Joint Committee for Structural Safety (JCSS), Probabilistic Model Code, 2001.

[14] Rackwitz, R.: Optimization - the basis of code making and reliability verification. Structural Safety, 22 (2000), pp. 27-60.

[15] Fischer, K.,Viljoen, C., Köhler, J., Faber, M.H.: Optimal and acceptable reliabilities for structural design, Structural Safety, 76 (2019), pp. I49-I6I, 2019. https://doi.org/I0.10I6/j.strusafe.2018.09.002

[16] Kaszynska, M. and Nowak, A.S.:Target Reliability for Design and Evaluation of Bridges, Conference on Bridge Management 5, ed. Parke, G.A.R. and Disney, P. at University of Surrey, U.K., April, pp. 40 I408, 2005.

[17] Allen, D.E.: Criteria for design safety factors and quality assurance expenditure, $3^{\text {rd }}$ International Conference on Structural Safety and Reliability, Trondheim, Norway, 198I.

[18] Rackwitz, R.: Optimization and risk acceptability based on the life quality index. Structural Safety, 24 (2002) Pp. 297-331.

[19] Hingorani, R., Tanner, P., Zanuyb, C.: Life safety risk-based requirements for concrete structures in accidental situations caused by gas explosions, Structural Safety 76 (2019) Pp. 184-I 96.

[20] Imhof, D. Risk assessment of existing bridge structures. PhD Thesis. University of Cambridge, UK. 2004.

[2I] Diamantidis, D., Holický, M., Jung,K.: Assessment of existing structures - on the applicability of the JCSS recommendations, Aspects of Structural Reliability, in honor of Prof. Rackwitz, Herbert Utz Verlag, Munich, Germany, 2007.

[22] Steenbergen, R.D.J.M., Sykora, M., Diamantidis, D., Holicky, M., A.C.W.M.Vrouwenvelder, A.C.W.M.: Target reliability levels for assessment of existing structures based on economic optimization and human safety criteria, Structural Concrete Journal 16 (2015), pp. 323-332.

[23] Sykora, M., Diamantidis, D., Holicky, M., Jung, K.: Target Reliability for Existing Structures Considering Economic and Societal Aspects, Structure and Infrastructure Engineering 13 (2017), pp. 181-194. 